\title{
Interfacial agent effect on rheological response and crystallite characteristics in germicidal polypropylene/titanium dioxide nanocomposites
}

\author{
Cristina Serrano, ${ }^{a}$ Jorge A Ressia, ${ }^{b, c}$ Enrique M Vallés, ${ }^{b}$ \\ Marta Fernández-García ${ }^{\mathrm{a}}$ and María L Cerrada ${ }^{\mathrm{a} *}$
}

\begin{abstract}
Germicidal nanocomposites based on metallocene isotactic polypropylene (iPP) and titanium dioxide $\left(\mathrm{TiO}_{2}\right.$ ) nanoparticles have been prepared at a constant $\mathrm{TiO}_{2}$ content of $\mathbf{2} \mathrm{wt} \%$. Different quantities of a polypropylene wax partially grafted with maleic anhydride (PP-g-MAH) are employed to improve the polymer-nanoparticle compatibility. Remarkable biocidal capabilities of these $\mathrm{TiO}_{2}$ nanocomposites have been found and their crystalline structure and thermal and rheological responses explored. Several very interesting features have been found in these germicidal nanocomposites. On the one hand, rheological parameters do not change significantly with respect to those exhibited by pure iPP. This is extremely advantageous for the processing of these compounds since they can be transformed under similar conditions to those employed for iPP. On the other hand, the existence of two polymorphs is observed independent of the amount of compatibilizer used. The enhancement in polymernanoparticle interactions by effect of the interfacial (PP-g-MAH) component is appraised looking at dynamical mechanical relaxations as a function of temperature and at crystallization processes of the various nanocomposites.
\end{abstract}

(c) 2012 Society of Chemical Industry

Keywords: $\mathrm{TiO}_{2}$ nanoparticles; polypropylene; polymorphs; nanocomposites; rheology; crystallites

\section{INTRODUCTION}

Mixtures of polymers and particles occur in a variety of practically important applications such as paints, coatings and rheological modifiers. $^{1,2}$ In many of these applications, the size of the polymer molecule, i.e. the length scale controlling polymer physics, is much smaller than the size of the particle. This limit, termed the 'colloid limit', is also the regime that has seen many advances in models and simulation approaches for predicting the equilibrium and dynamic properties of polymer-particle mixtures. ${ }^{3}$ More recent applications have involved polymer-particle mixtures in the 'nanoparticle limit', where the size of polymer molecule is comparable with or larger than the particle size. For instance, in materials broadly termed as polymer nanocomposites, nanoparticles of various shapes with sizes in the range $5-50 \mathrm{~nm}$ are routinely dispersed in polymeric matrices to enhance some of their properties. ${ }^{4-6}$ Many such efforts are motivated by experimental observations, which have suggested that either significant improvements in specific properties or the appearance of unexpected behaviours may occur when low contents of nanoparticles (in proportions usually less than $8 \mathrm{wt} \%$ ) are incorporated into the structure of a given polymer. In contrast, modest property enhancements are usually achieved in conventional composites if the same amount of colloidal-size particles is incorporated to the polymer. $^{7-26}$

Insight into how nanoparticles influence the associated morphological structure and system dynamics of polymer-nanoparticle mixtures is only beginning to emerge. The progress of knowledge in these areas will be a key to develop design rules for novel engineering materials with desired properties. Most of the improvements reported in the literature are usually attributed to the dramatic increase of the interfacial area between filler and polymer. ${ }^{27,28}$ Another important variable for the enhancement of properties is the degree of nanofiller dispersion within the polymeric matrix. In addition to these two aspects, the polymer-particle and particle-particle interactions significantly determine the final properties exhibited by polymer-based nanocomposites.

In a series of recent publications, an intimate contact has been stated between the two components of nanocomposites based on ethylene-(vinyl alcohol) copolymers and $\mathrm{TiO}_{2}$. This contact leads to their extraordinary biocidal behaviour. ${ }^{21,22,24}$ In fact, the existence of energy/charge transfer(s) through the

\footnotetext{
Correspondence to: María L Cerrada, Instituto de Ciencia y Tecnología de Polímeros (ICTP-CSIC), C/ Juan de la Cierva 3, 28006 Madrid, Spain.

E-mail:mlcerrada@ictp.csic.es

a Instituto de Ciencia y Tecnología de Polímeros (ICTP-CSIC), C/Juan de la Cierva 3, 28006 Madrid, Spain

b Planta Piloto de Ingeniería Química - PLAPIQUI (UNS-CONICET), Camino La Carrindanga Km 7, 8000 Bahía Blanca, Argentina

c Comisión de Investigaciones Científicas de la Provincia de Buenos Aires (CIC), La Plata, Argentina
} 
polymer-oxide interface and the subsequent development of new electronic states within the nanocomposite system ${ }^{22}$ are the causes behind this striking germicidal capability. This optimal antimicrobial activity has been also reported in other $\mathrm{TiO}_{2}$ nanocomposites ${ }^{23,25,29}$ where isotactic polypropylene (iPP) was used as polymeric matrix. In these two polymeric nanocomposite systems, efficient interactions between the organic and inorganic components allow the transfer of the inherent capability of $\mathrm{TiO}_{2}$ of degrading cell components of microorganisms ${ }^{30,31}$ to the whole system.

Viscoelastic properties in the molten state of nanofiller/polymer composites have both practical and basic importance since they are related to nanocomposite processing, dynamics and microstructure. The general behaviour reported in the literature for oscillatory shear rheological measurements at low frequencies is that the linear rheological properties evolve from a liquidlike to a solid-like behaviour as the nanoparticle concentration increases. Then, this technique also provides a tool to estimate the percolation threshold, corresponding to the onset of solid-like behaviour. Bahloul et al. have recently studied the morphology and rheological properties of polypropylene/ $\mathrm{TiO}_{2}$ nanocomposites prepared using an in situ sol-gel method. ${ }^{32}$ They found that a $\mathrm{TiO}_{2}$ concentration as low as $2.9 \mathrm{wt} \%$ strongly alters the terminal relaxation zone of the viscoelastic spectrum with significant increase in the values of $G^{\prime}$ and $\eta^{*}$ with respect to those exhibited by unfilled iPP. Concentrations of $\mathrm{TiO}_{2}$ above $6 \mathrm{wt} \%$ induce a solid-like behaviour in the nanocomposites, which includes a nonterminal zone of relaxation. By contrast, those authors also found that regular blends of the same iPP with commercially available anatase $\mathrm{TiO}_{2}$ particles (average particle size of $525 \mathrm{~nm}$ ) for a similar composition range do show a regular terminal zone. Dangtungee and Supaphol ${ }^{33}$ studied the melt rheology and extrudate swell of $\mathrm{iPP} / \mathrm{TiO}_{2}$ composites prepared with commercially available rutile-type $\mathrm{TiO}_{2}$ nanoparticles with different surface characteristics (neat, $\mathrm{SiO}_{2}$-coated and stearic acid-coated) in proportions ranging from 5 to $30 \mathrm{wt} \%$. They found slight to moderate increase in viscosity and lesser degree of extrudate swelling depending on the concentration of $\mathrm{TiO}_{2}$ particles and their surface characteristics. Changes were more important at a given concentration when $\mathrm{SiO}_{2}$-coated nanoparticles were employed and less significant for the stearic acid-coated ones.

The primary aim of the work reported in this article was to obtain a deeper understanding of the influence of interfacial agent content on the rheological behaviour and crystalline characteristics exhibited by $\mathrm{iPP} / \mathrm{TiO}_{2}$ nanocomposites with biocidal properties. These $\mathrm{iPP} / \mathrm{TiO}_{2}$ hybrids are rather different from those previously reported, ${ }^{32,33}$ because of their extraordinary germicidal capability and because of the presence of a third individual component (the compatibilizer), the method used for their preparation and the initial size of the $\mathrm{TiO}_{2}$ nanoparticles, among other variables. In order to verify if $\mathrm{TiO}_{2}$ incorporation may induce significant changes in iPP processability and affect the final properties of the resulting materials, the evaluation of their rheological properties in the melt is of major importance. Moreover, the influence of different interfacial agent contents at a given $\mathrm{TiO}_{2}$ incorporation on the polymorphic behaviour and phase transitions of the metallocene iPP matrix was also studied to assess final properties as important as viscoelastic and thermal performance in the resulting hybrid materials. Therefore, several characterization techniques were used for this investigation: dynamic mechanical analysis under shear and tension in order to evaluate the viscoelastic behaviour in the molten and solid state, respectively, wide-angle X-ray scattering
(WAXS) and small-angle X-ray scattering (SAXS) using synchrotron radiation, DSC and TGA.

\section{EXPERIMENTAL}

\section{Nanocomposite preparation}

The $\mathrm{TiO}_{2}$ component (characteristic primary particle size below $10 \mathrm{~nm}$ ) was prepared using a microemulsion synthetic route as described previously. ${ }^{34,35}$ In brief, titanium(IV) isopropoxide (Aldrich) was added to an inverse emulsion containing an aqueous phase dispersed in $n$-heptane (Panreac), using Triton X-100 (Aldrich) as surfactant and 1-hexanol (Aldrich) as co-surfactant. The mixture was stirred for $24 \mathrm{~h}$, centrifuged, decanted, rinsed under stirring five consecutive times with methanol (twice), water (twice) and acetone (once) to eliminate any portion from the organic and surfactant media, dried at $110^{\circ} \mathrm{C}$ for $24 \mathrm{~h}$ and calcined at $500^{\circ} \mathrm{C}$ for $2 \mathrm{~h}$.

A commercially available metallocene-catalysed iPP (Basell Metocene X50081: melt flow index of $60 \mathrm{~g} / 10 \mathrm{~min}$ at $230{ }^{\circ} \mathrm{C} / 2.16 \mathrm{~kg}$, ASTM D1238), meeting US Food and Drug Administration requirements for food contact (Federal Regulations, 21 CFR 177.1520), was used as polymeric matrix in the preparation of the $\mathrm{iPP} / \mathrm{TiO}_{2}$ nanocomposites. Polypropylene wax partially grafted with maleic anhydride (PP-g-MAH) was used as interfacial agent (Licomont ${ }^{\circledR}$ AR 504 fine grain from Clariant) in compositions of $0,30,50$ and $80 \mathrm{wt} \%$ with respect to the content of $2 \mathrm{wt} \% \mathrm{TiO}_{2}$ nanoparticles $(0,0.6,1$ and $1.6 \mathrm{wt} \%$ overall loadings, respectively). The resultant three-component nanocomposites were labelled as iPPxTi2, with $x$ being the compatibilizer content related to the $2 \mathrm{wt} \%$ content of $\mathrm{TiO}_{2}$. These nanocomposites were prepared through straightforward melt processing in an internal mixer with volumetric capacity of $3 \mathrm{~cm}^{3}$ at $160^{\circ} \mathrm{C}$ and at $60 \mathrm{rpm}$ for $5 \mathrm{~min}$. Previously $\mathrm{TiO}_{2}$ nanoparticles were sonicated in an ultrasonic device to minimize their aggregation and maximize the performance of resultant nanocomposites.

Films were obtained by compression moulding in a Collin press between hot plates $\left(175^{\circ} \mathrm{C}\right)$ at a pressure of $1.5 \mathrm{MPa}$ for $5 \mathrm{~min}$. Two different thermal treatments were applied. The first thermal treatment consisted of a slow cooling from the molten state to room temperature. In this case the films were obtained at the inherent cooling rate of the press $\left(c a{ }^{\circ} \mathrm{C} \mathrm{min}^{-1}\right)$ after the power was switched off. For the second thermal treatment, after melting the polymer, a fast quench between the plates of the press refrigerated with cold water $\left(100^{\circ} \mathrm{C} \mathrm{min}^{-1}\right)$ was applied. The samples from the first treatment are labelled as $\mathrm{S}$ specimens, while those obtained from the second treatment are labelled as $\mathrm{Q}$ samples. Post-crystallization of iPP within the just-processed films is a well-known effect. To avoid it, all of films were kept at room temperature for at least three days before performing their characterization.

\section{Sample characterization}

The XRD profile of $\mathrm{TiO}_{2}$ nanoparticles was obtained with a Seifert diffractometer using Ni-filtered $\mathrm{Cu} \mathrm{K} \alpha$ radiation. Particle size was calculated from this pattern using the Willianson-Hall method, which takes into account the strain and particle size contributions to the XRD peak broadening.

Transmission electron microscopy (TEM) was performed at room temperature using a $200 \mathrm{kV}$ JEM-2000 FX JEOL microscope to analyse material homogeneity. Samples were embedded in Spurr resin (cured at $60^{\circ} \mathrm{C}$ for $48 \mathrm{~h}$ ) to obtain parallel cuts of 
the film surface in thin sections $(80 \mathrm{~nm})$ using ultramicrotomy (Reichert-Jung Ultracut E). Specimens were then picked up on copper grids and coated with a thin layer of carbon graphite (MED 010 Balzers evaporator) to improve heat conduction.

Antimicrobial tests were performed using a Pseudomona aeruginosa PAO clinical isolate PBCLOp11 from burn wound infections. Cells were streaked from a glycerol stock onto an appropriate agar plate, grown overnight at $37^{\circ} \mathrm{C}$ and subsequently used for photochemical cell viability assays. To study the antimicrobial activity of the $\mathrm{TiO}_{2}$ nanomaterials, they were contacted with a solution containing microbial cells (about $10^{-9}$ CFU $\mathrm{mL}^{-1}$ ) suspended in $1 \mathrm{~mL}$ of broth solution. The system was placed in a UV spectrometer chamber (UVIKON 930) and irradiated with UV light of $280 \mathrm{~nm}$ for various periods of time. Loss of viability after each exposure time was determined by the viable count procedure using Luria-Bertani agar plates after serial dilution $\left(10^{-2}\right.$ to $\left.10^{-5}\right)$. All plates were incubated for $24 \mathrm{~h}$ prior to enumeration at the temperatures mentioned above, specific for each microorganism. A minimum of three experimental runs was carried out to determine the antimicrobial activity.

The rheological characterization was carried out in smallamplitude oscillatory shear mode using a dynamic rotational rheometer from Rheometrics Inc. (Rheometrics Dynamic Analyzer RDA-II). The tests were performed using parallel plates of $25 \mathrm{~mm}$ in diameter, at a frequency range between 0.1 and $500 \mathrm{rad} \mathrm{s}^{-1}$, and a temperature range of $170-250^{\circ} \mathrm{C}$. All tests were carried out at small strains in order to ensure the linearity of the dynamic responses. ${ }^{36}$ The series of frequency sweeps were repeated twice with the same sample at various strains in the range of linear viscoelasticity. Excellent agreement was found between these results in all cases.

Viscoelastic relaxations in the solid state were measured with a Polymer Laboratories MK II dynamic mechanical thermal analyser working in tensile mode. Strips around $4.5 \mathrm{~mm}$ in width and $18 \mathrm{~mm}$ in length were cut from the moulded sheets. The storage modulus, $E^{\prime}$, loss modulus, $E^{\prime \prime}$, and the loss tangent, $\tan \delta$, of each sample were determined over a temperature range from -150 to $150^{\circ} \mathrm{C}$ at fixed frequencies of $3,10,30$ and $50 \mathrm{~Hz}$, and at a heating rate of $1.5^{\circ} \mathrm{C} \mathrm{min}-1$. The apparent activation energy values were calculated according to an Arrhenius-type equation, considering an accuracy of $\pm 1^{\circ} \mathrm{C}$ in the temperature assignment of $\tan \delta$ maxima.

WAXS patterns for the neat iPP matrix and the various nanocomposites were recorded in reflection mode at room temperature using a Bruker D8 Advance diffractometer equipped with a Goebel mirror and a PSD Vantec detector (from Bruker, Madison, Wiscon$\sin )$. Cu K $\alpha$ radiation was used. The equipment was calibrated with various standards. A step scanning mode was employed for the detector, with a $2 \theta$ step of $0.024^{\circ}$ and $0.2 \mathrm{~s}$ per step. The WAXS degree of crystallinity, $f_{\mathrm{c}}^{\text {WAXS }}$, was determined from the X-ray diffractograms after subtraction of the amorphous profile. ${ }^{37}$

An X-ray synchrotron study was performed in the softcondensed matter beamline A2 at Hasylab (Hamburg, Germany), working at a wavelength of $0.150 \mathrm{~nm}$. The experimental setup included a specimen holder, a MARCCD detector for acquiring twodimensional SAXS patterns (sample-to-detector distance being $260 \mathrm{~cm}$ ) and a linear detector for one-dimensional WAXS measurements (distance $21 \mathrm{~cm}$ ). A sample of crystalline poly(ethylene terephthalate) was used for WAXS calibration and the different orders of the long spacing of rat-tail cornea $(L=65 \mathrm{~nm}$ ) were utilized for the SAXS detector. The two-dimensional X-ray diffractograms were processed using the A2tool program developed to support beamline $A 2$ data processing. The profiles were normalized to the primary beam intensity and the background from an empty sample was subtracted. All experiments comprise the heating of samples from 26 to $170{ }^{\circ} \mathrm{C}$ at $8{ }^{\circ} \mathrm{C} \mathrm{min}{ }^{-1}$. The data acquisition was done in frames of $15 \mathrm{~s}$.

Calorimetric analyses were carried out using a PerkinElmer DSC7 calorimeter connected to a cooling system and calibrated with various standards. The sample weights ranged from 6 to $9 \mathrm{mg}$ and the heating rate used was $8^{\circ} \mathrm{C} \mathrm{min}^{-1}$. For crystallinity determinations, $f_{c}^{\text {DSC }}$, a value of $209 \mathrm{~J} \mathrm{~g}^{-1}$ was taken as the enthalpy of fusion of a perfect crystalline material. ${ }^{38}$ The glass transition temperature was determined as the temperature where the specific heat increment was half the total one at the transition.

The weight loss was estimated by thermogravimetry using TA Instruments TGA Q500 equipment working under an oxidant atmosphere. The equipment was calibrated according to standard protocols. The sample weights ranged from 4 to $6 \mathrm{mg}$, and the heating rate was $10^{\circ} \mathrm{C} \mathrm{min}^{-1}$.

\section{RESULTS AND DISCUSSION}

Figure 1 displays the XRD profile of $\mathrm{TiO}_{2}$ nanoparticles (middle). This shows an anatase structure and a primary particle size of about $10 \mathrm{~nm}$ is determined. This figure also presents TEM micrographs for the iPP0T2 hybrid (left) and for the iPP80T2 one (right). Some micrometre-sized aggregates can be easily observed in the case of iPPOTi2 while the $\mathrm{TiO}_{2}$ nanoparticles are well dispersed within the polymer exhibiting nanometric aggregates ranging from 10 to $200 \mathrm{~nm}$, with an average size (Feret diameter) of $80 \mathrm{~nm}( \pm 20 \mathrm{~nm})$. Accordingly, the nanometric dispersion of the oxide is rather significant in the iPP80T2 nanocomposite.

An excellent ability for the destruction of regular bacteria such as Bacillus stearothermophilus, Escherichia coli, Streptococcus aureus and Pichia jadini, and other microorganisms widely present in the environment that cause infections and serious illness, such
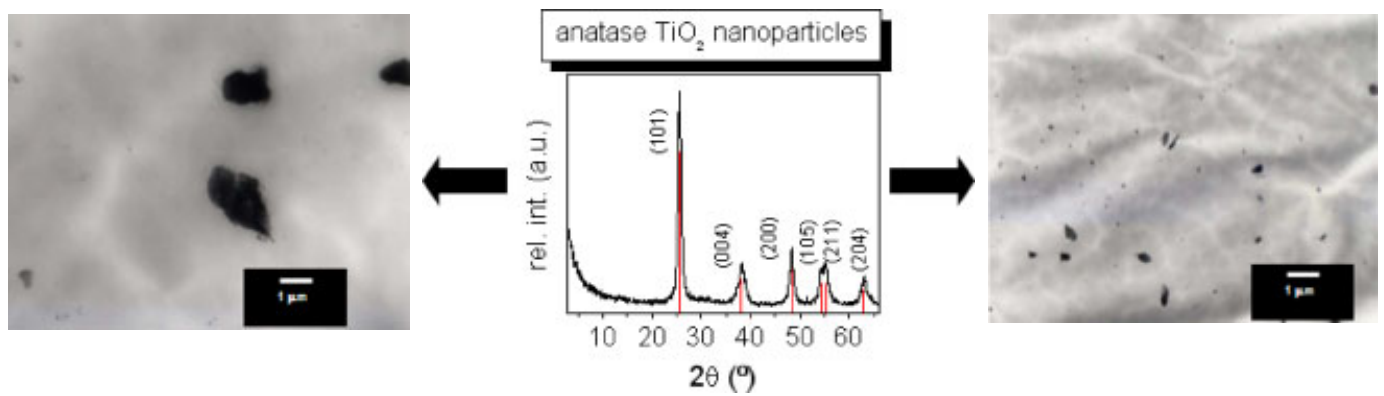

$2 \theta(9)$

Figure 1. XRD pattern of the $\mathrm{TiO}_{2}$ component (middle) and TEM micrographs of iPP0T2 (left) and iPP80T2 (right) nanocomposites. 

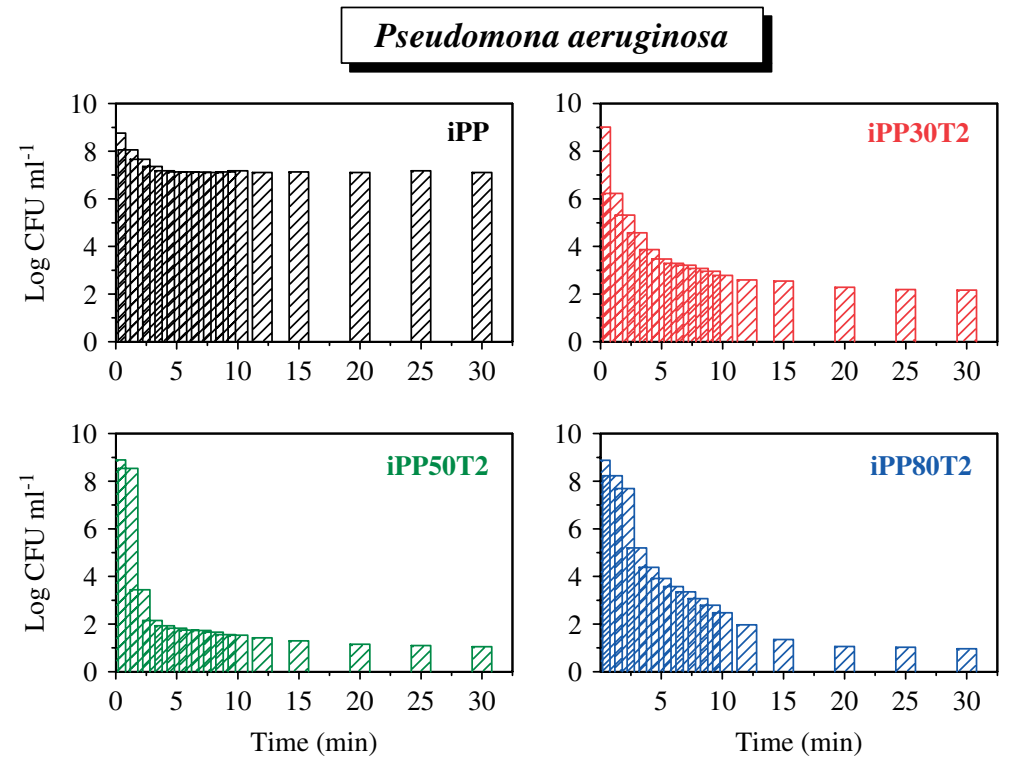

Figure 2. Process come-up time logarithmic reduction of microorganism population suspended in Luria-Bertani medium. Survival curves of $P$. aeruginosa as a function of irradiation time for iPP control and iPPxTi2 samples. ${ }^{29}$

as Pseudomonas aeruginosa and Enterococcus faecalis, has been found in $\mathrm{TiO}_{2}$ nanoparticle/polypropylene nanocomposites $23,25,29$ compared with other biocidal agents. Figure 2 shows this germicidal activity against the $P$. aeruginosa microbe. The blank experiment in the presence of the iPP matrix demonstrates the relative innocuousness of UV radiation, and then a maximum of about 1.5 log-reductions. Incorporation of $\mathrm{TiO}_{2}$ has an important impact on the cell inactivation exhibited by the nanocomposites with respect to the blank test (measuring UV influence in the presence of neat iPP). Accordingly, an initial increase on the elimination velocity is clearly observed as well as a further decrease of final log-reduction at the end of the experiments. The greatest initial reduction rate is observed for the iPP50Ti2 nanocomposite where the almost complete cell inactivation of this microorganism is reached, accounting for a log-reduction of near 9 units, for both iPP50Ti2 and iPP80Ti2 specimens.

These nanocomposites present important and specific biocidal properties. Nevertheless, incorporation of the nanoparticles and compatibilizer might alter considerably the processing conditions when compared with neat iPP. Thus, rheological measurements are required to provide this knowledge. Rheology of polymer melts depends strongly on the temperature at which the measurement is carried out. In the current study, the experiments were performed at $170,190,210,230$ and $250^{\circ} \mathrm{C}$, taking $210^{\circ} \mathrm{C}$ as the reference temperature $\left(T_{\text {ref }}\right)$ in order to apply the time-temperature superposition principle. It is well known that for thermorheologically simple materials, bi-logarithmic plots of the isotherms of $G^{\prime}(\omega), G^{\prime \prime}(\omega)$ and dynamic viscosity $\eta^{\prime}(\omega)$ can be superimposed by horizontal shifts, $\log \left(\underline{a}_{\top}\right)$, along the $\log (\omega)$ axis, and vertical shifts given by $\log \left(b_{T}\right)$ such that ${ }^{36}$

$$
\begin{aligned}
b_{\top} G^{\prime}\left(a_{\mathrm{T}} \omega, T\right) & =G^{\prime}\left(\omega, T_{\text {ref }}\right) \\
b_{\mathrm{T}} G^{\prime \prime}\left(a_{\mathrm{T}} \omega, T\right) & =G^{\prime \prime}\left(\omega, T_{\text {ref }}\right) \\
\left(b_{\mathrm{T}} / a_{\mathrm{T}}\right) \eta^{\prime}\left(a_{\mathrm{T}} \omega, T\right) & =\eta^{\prime}\left(\omega, T_{\text {ref }}\right)
\end{aligned}
$$

All isotherms measured for neat iPP and for various iPPxTi2 can be superimposed in this way, allowing attainment of time-temperature master curves. The curves obtained using these shift factors for $G^{\prime}(\omega)$ and $G^{\prime \prime}(\omega)$ of pure metallocene iPP and the iPPxTi2 hybrids with various weight percentages of interfacial agent are depicted in Fig. 3. In order to better visualize the
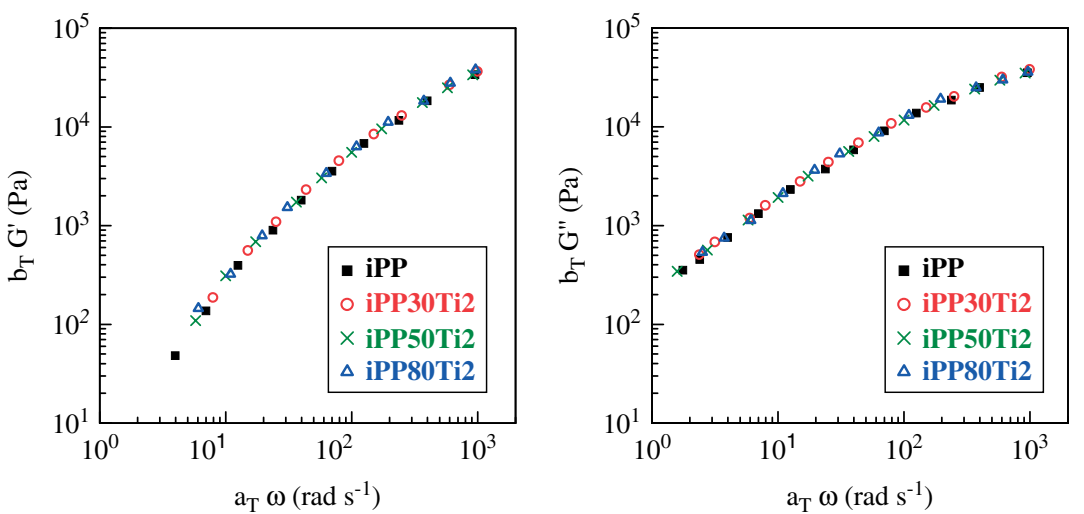

Figure 3. Reduced frequency dependence of storage modulus, $G^{\prime}(\omega)$, and loss modulus, $G^{\prime \prime}(\omega)$, of metallocene iPP and its nanocomposites with $\mathrm{TiO}_{2}$. 


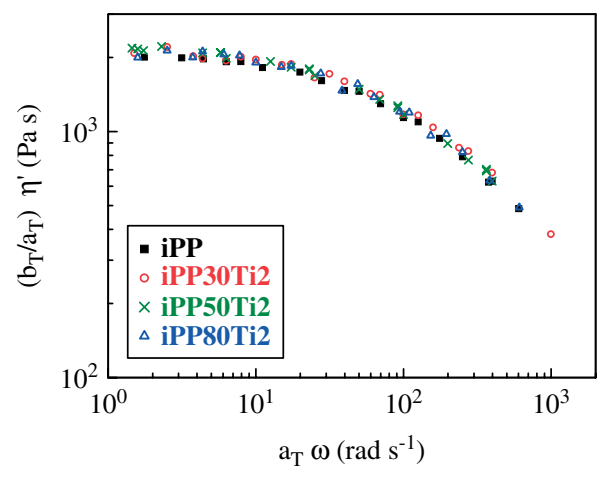

Figure 4. Reduced frequency dependence of dynamic viscosity, $\left(b_{T} / a_{T}\right) \eta^{\prime}$, of metallocene iPP and its nanocomposites with $\mathrm{TiO}_{2}$.

differences in the rheological behaviour of the prepared iPPxTi2 nanocomposites, only some of the experimentally obtained data points are included in the figure. The viscoelastic behaviour in the molten state found for all of specimens is quite similar, the values for the nanocomposites being slightly higher than those for the neat iPP. The different samples with specific compatibilizer contents exhibit curves that are superimposable mostly independent of interfacial agent content. Moreover, the apparent activation energies can be estimated from Arrhenius plots of the data considering those temperature shift factors achieved. The values determined are 38, 39, 37 and $36 \mathrm{~kJ} \mathrm{~mol}^{-1}$ for iPP, iPP30Ti2, iPP50Ti2 and iPP80Ti2, respectively. Incorporation of a small amount of $\mathrm{TiO}_{2}$ nanoparticles and interfacial agent (iPP30Ti2 hybrid) increases slightly the activation energy with respect to that presented by the neat matrix. However, apparent activation energy values slightly decrease as compatibilizer content is increased.

This similarity in the rheological response results in similar dynamic viscosity curves for the various nanocomposites studied in this work, as shown in Fig. 4. Therefore, the reinforcement induced in the viscoelastic properties of the melt by the $\mathrm{TiO}_{2}$ nanoparticles is quite weak. The fact that these nanocomposites show an excellent biocidal activity with respect to the practically non-existent one for neat iPP and that their viscoelastic responses in the melt are rather analogous to those seen for pure iPP is quite advantageous since the nanocomposites have an attractive biocidal specificity with almost no change in the properties that influence their processing conditions.

The viscoelastic response in the solid state, i.e. the films obtained after processing, is depicted in Fig. 5 for quenched specimens. Three relaxation processes are observed in $\tan \delta$ plots, labelled as

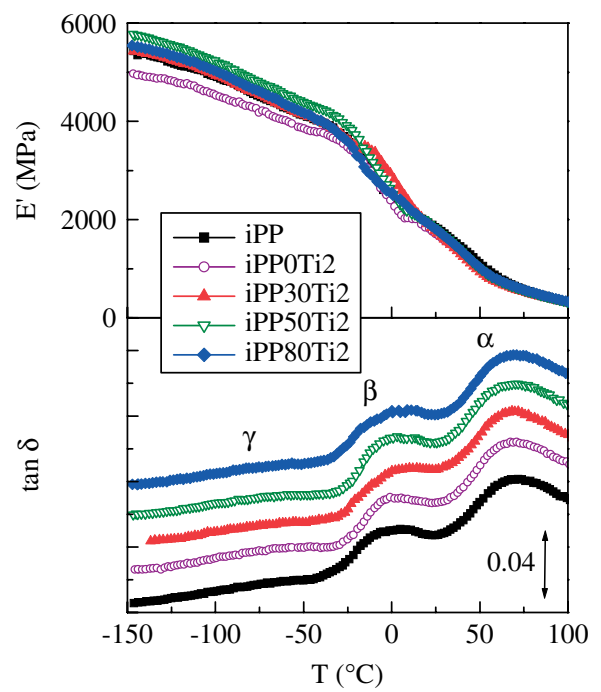

Figure 5. Temperature dependence of storage modulus and loss tangent $(\tan \delta)$ curves of neat iPP specimen and various nanocomposites quenched from the melt. Tan $\delta$ curves have been vertically shifted for clarity.

$\gamma, \beta$ and $\alpha$ in order of increasing temperature. The $\alpha$ relaxation is related to motions within the polymeric crystalline phase, especially to defect diffusion. ${ }^{39}$ Characteristics of this process, such as location and relaxation time distribution, are rather independent of $\mathrm{TiO}_{2}$ nanoparticle incorporation and content of interfacial agent compared with those exhibited by iPP homopolymer. However, the absolute value is slightly greater for the nanocomposites indicating than more crystallites contribute to this mechanism.

The relaxation that takes place at $c a 0^{\circ} \mathrm{C}$ is ascribed to generalized motions of long-chain segments that occur during the glass transition. The cooperative nature of this movement explains the great decrease in $E^{\prime}$ found in this temperature range. Its magnitude in $\tan \delta$ does not vary with the introduction of the inorganic component, a fact that seems to point out that nanoparticles can be accommodated within the amorphous regions of IPP without a substantial entropic penalty. Consequently, the $\beta$ relaxation position is only slightly affected (Table 1).

The other relaxation process, labelled as $\gamma$, ascribed to rotational motions of methyl groups from polypropylene, is observed at temperatures slightly lower than that related to cooperative motions. It does actually appear as a shoulder and not as a well-defined peak even for the iPP homopolymer (Fig. 5).

Regarding the elastic component of Young's modulus, the values for the different quenched specimens are rather similar

Table 1. Relaxation temperatures ( $\tan \delta$ basis, at $3 \mathrm{~Hz}$ ) for the various processes and storage modulus values $\left(\mathrm{E}^{\prime}, \mathrm{MPa}\right)$ at different temperatures $\left(-120,25\right.$ and $\left.100^{\circ} \mathrm{C}\right)$ for the iPPTiO homopolymer and its nanocomposites with various interfacial agent contents under the two thermal treatments

\begin{tabular}{|c|c|c|c|c|c|c|c|c|c|c|c|c|}
\hline \multirow[b]{2}{*}{ Sample } & \multicolumn{6}{|c|}{$\mathrm{S}$ thermal treatment } & \multicolumn{6}{|c|}{$\mathrm{Q}$ thermal treatment } \\
\hline & $T_{\gamma}\left({ }^{\circ} \mathrm{C}\right)$ & $T_{\beta}\left({ }^{\circ} \mathrm{C}\right)$ & $T_{\alpha}\left({ }^{\circ} \mathrm{C}\right)$ & $\begin{array}{c}\mathrm{E}^{\prime}\left(-120^{\circ} \mathrm{C}\right) \\
(\mathrm{MPa})\end{array}$ & $\begin{array}{c}\mathrm{E}^{\prime}\left(25^{\circ} \mathrm{C}\right) \\
(\mathrm{MPa})\end{array}$ & $\begin{array}{c}\mathrm{E}^{\prime}\left(100^{\circ} \mathrm{C}\right) \\
(\mathrm{MPa})\end{array}$ & $T_{\gamma}\left({ }^{\circ} \mathrm{C}\right)$ & $T_{\beta}\left({ }^{\circ} \mathrm{C}\right)$ & $T_{\alpha}\left({ }^{\circ} \mathrm{C}\right)$ & $\begin{array}{c}\mathrm{E}^{\prime}\left(-120^{\circ} \mathrm{C}\right) \\
(\mathrm{MPa})\end{array}$ & $\begin{array}{c}\mathrm{E}^{\prime}\left(25^{\circ} \mathrm{C}\right) \\
(\mathrm{MPa})\end{array}$ & $\begin{array}{c}\mathrm{E}^{\prime}\left(100^{\circ} \mathrm{C}\right) \\
(\mathrm{MPa})\end{array}$ \\
\hline iPP & -61.0 & 5.0 & 77.5 & 4850 & 1750 & 280 & -72.0 & 0.0 & 67.5 & 5100 & 1850 & 310 \\
\hline іРP0Ti2 & -61.0 & 4.0 & 78.0 & 5400 & 2050 & 300 & -68.5 & 0.5 & 68.5 & 4800 & 1700 & 300 \\
\hline ¡PP30Ti2 & -61.0 & 3.5 & 75.5 & 5800 & 2150 & 300 & -70.0 & 1.5 & 68.5 & 5200 & 1750 & 310 \\
\hline iPP50Ti2 & -60.0 & 3.5 & 73.5 & 5250 & 2050 & 300 & -69.5 & 1.5 & 68.5 & 5500 & 1800 & 320 \\
\hline iPP80Ti2 & -60.0 & 2.5 & 73.5 & 6050 & 2200 & 320 & -70.0 & 2.0 & 68.5 & 5300 & 1800 & 320 \\
\hline
\end{tabular}


except for the nanocomposite sample without compatibilizer that shows relatively low values at low temperatures. This feature seems to indicate that rigidity is diminished if there is not a good interfacial adhesion while this mechanical parameter is quite independent of the content of interfacial agent in the other nanocomposites, the iPP50Ti2 nanocomposite being that with the highest values of storage modulus at low temperature. Nevertheless, the role of interfacial adhesion is not as straightforward in the slowly cooled specimens. Stiffness is also much affected by crystallite characteristics such as degree of crystallinity and crystallite size as well as presence of different crystalline polymorphs and their ratio. As will be discussed below, the $\gamma$ crystallites are preferentially developed under slow cooling from the melt and these crystals are smaller than the monoclinic $\alpha$ ones. Accordingly, smaller values of storage modulus are observed at low temperature for iPP50Ti2 compared to iPPOTi2, although the difference is not too significant. The former sample is the one with the highest content of $\gamma$ crystals, and iPPOTi2 displays poorer adhesion at interfaces. The balance of all these variables seems now to be favourable for slowly cooled iPPOTi2.

Other important factors to be considered are those related to knowing how the interfacial agent content and the thermal history imposed on these nanocomposites affect their final crystalline structure. Figure 6 clearly shows the coexistence at room temperature of the $\alpha$ and $\gamma$ polymorphs in the whole series of the slowly cooled samples $(\mathrm{S})$ in the press. ${ }^{40}$ The most typical and the most stable crystalline structure is the monoclinic $\alpha$ form that was first characterized by Natta and Corradini. ${ }^{41}$ The orthorhombic $\gamma$ modification is easily identified because of its characteristic (117) diffraction peak at ca $20^{\circ}$ in the $2 \theta$ profiles. ${ }^{42}$ This polymorph is specially favoured in the case of iPP synthesized using metallocenic catalysts due to the presence of errors homogeneously distributed among the different polymer chains ${ }^{43}$ A different result is observed for all the quenched samples where the $\alpha$ form is preferentially developed.

The proportion of these two crystalline phases present in the various specimens can be determined from the deconvolution of the diffractograms shown in Fig. 6. The procedure used is the following. The amount of amorphous phase is estimated from comparison with the diffraction profile corresponding to a totally amorphous, elastomeric polypropylene sample, obtained using the same diffractometer and configuration. ${ }^{42}$ In this way, the total $\mathrm{X}$-ray crystallinity is determined, and the corresponding values are presented in the upper plot of Fig. 7. As expected, the degree of crystallinity is significantly lower for the $\mathrm{Q}$ metallocenic iPP

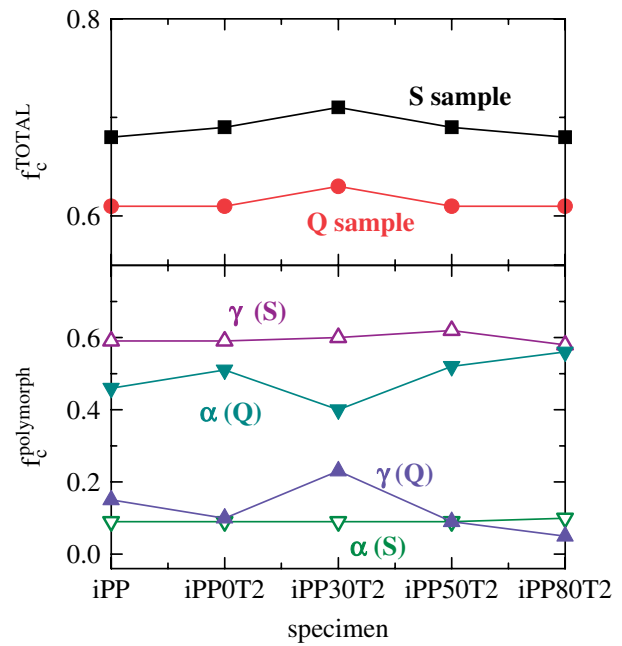

Figure 7. Overall crystallinity and $\gamma$ and $\alpha$ polymorph contents estimated from WAXS for all specimens processed under two thermal treatments as a function of interfacial agent content.

specimens. In this case, crystallization takes place at conditions far from equilibrium and the fast cooling applied limits even more the development of crystallites and their perfection. Incorporation of $\mathrm{TiO}_{2}$ nanoparticles does not much affect the degree of crystallinity, although, independent of the thermal treatment imposed, slightly higher values are achieved with the addition of a small amount of nanoparticles.

The diffractograms representing the pure crystalline components of each specimen are obtained after subtracting the scaled amorphous profile. These pure crystal profiles can be used for the subsequent deconvolution of the diffraction peaks corresponding to each modification. In this way the amount of the different polymorphs can be determined. The present diffraction peaks were fitted to Voigt profiles as one of the best options. The proportions of the two modifications were obtained from the relative areas of the diffractions at $2 \theta=18.8^{\circ}$ and $20.2^{\circ}$. Due to the diffraction peaks overlapping, the results will evidently undergo a slight change using different profiles for the fitting. In addition, this procedure assumes that relative areas of the diffractions at $18.8^{\circ}$ and $20.2^{\circ}$ in relation to total crystalline area are, respectively, the same in samples with $100 \%$ of $\alpha$ or $\gamma$ modification. The proportions of the various modifications for the different specimens are those presented in the bottom plot of Fig. 7. It is important to
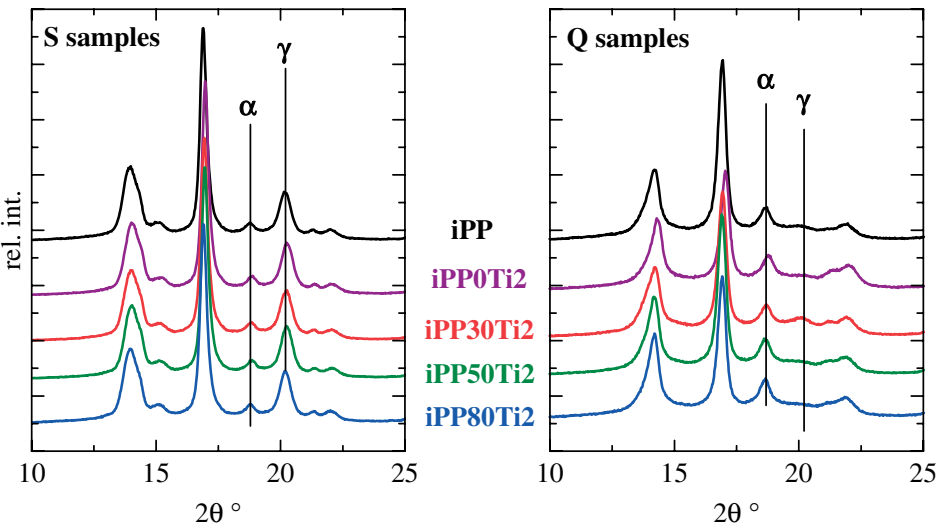

Figure 6. WAXS patterns of pure iPP and nanocomposite samples for the two thermal treatments evaluated. 

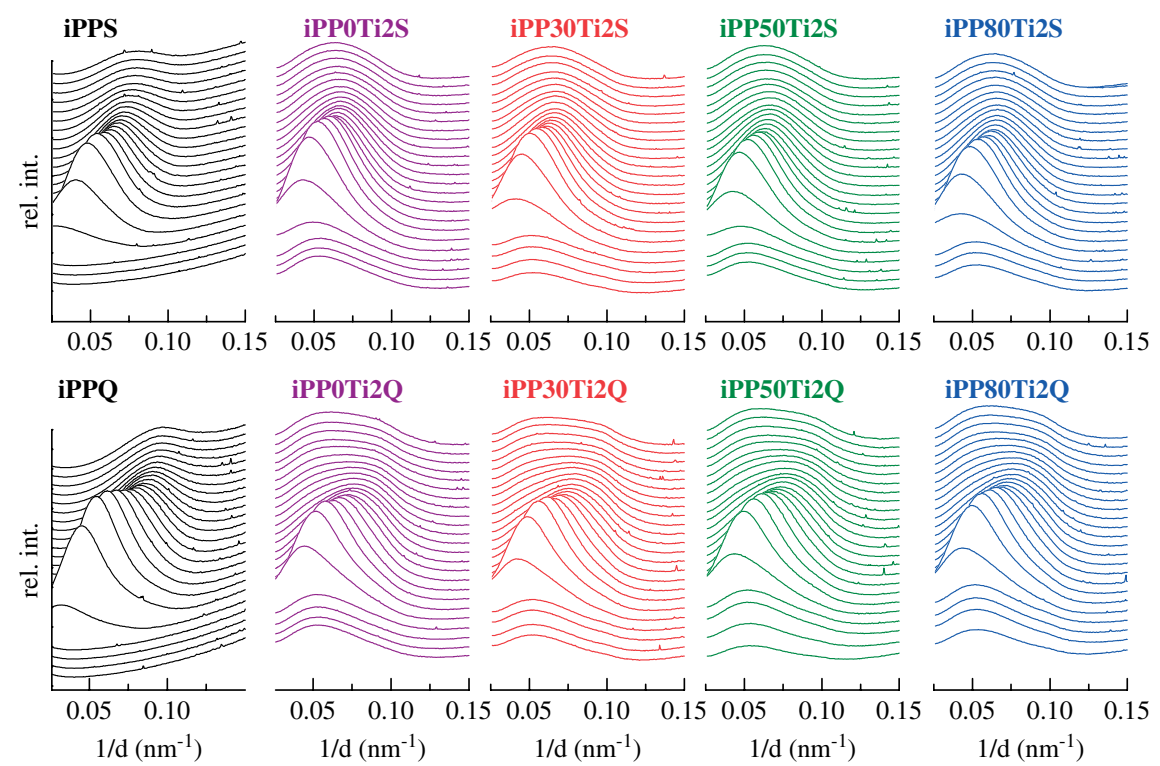

Figure 8. Global real-time SAXS profiles obtained with synchrotron radiation for all samples under the two thermal treatments in a melting experiment at $8{ }^{\circ} \mathrm{C} \mathrm{min}-1$. Only one in every three frames is plotted for clarity.

subtract first the amorphous component, since it shows a clearly asymmetric profile, ${ }^{37}$ with a maximum at $2 \theta$ around $15.5^{\circ}$ and a shoulder centred at around $20^{\circ}$. As commented, a reverse $\alpha / \gamma$ ratio is obtained depending on the thermal treatment: a majority of $\alpha$ crystals is attained in the $\mathrm{Q}$ samples and a higher proportion of $\gamma$ polymorph in the $S$ samples. In addition, a near constancy is observed in the proportion of $\alpha$ and $\gamma$ polymorphs for the S specimens, while either a decreasing tendency in the $\gamma$ polymorph development or a growing trend in the monoclinic $\alpha$ form are seen for the $\mathrm{Q}$ samples as interfacial agent content increases, except for the iPP30Ti2 nanocomposite. The amount of compatibilizer is not enough to allow a smooth interface contact between the two major components in this iPP30Ti2 hybrid, ${ }^{30}$ and the interfacial agent seems to interact with the matrix more efficiently than with the nanoparticles because of their higher chemical affinity. It should be taken into account that this third component is a wax. Therefore, it is able to develop a larger crystallinity than other iPPs with higher molecular weight and the $\gamma$ polymorph is also favoured to the detriment of the $\alpha$ form - although it is a minority - even under this adverse fast cooling from the melt.

Concerning the crystallite size, real-time variable-temperature SAXS experiments were performed to estimate long spacing values. Figure 8 shows the initial profiles during heating for all of the samples analysed under the two thermal treatments imposed. Several characteristics are common for all of these specimens independent of thermal history: (a) an important shift to lower 1/d values of the peak related to the long spacing takes place with temperature, indicating improvement in perfection of crystallites and their thickening and (b) a periodicity peak is observed for all the nanocomposites after melting of the polymeric matrix. This correlation peak is ascribed to a characteristic spacing between $\mathrm{TiO}_{2}$ nanoparticles. ${ }^{32}$ Therefore, two specific contributions should be initially taken into consideration: one related to differences in electronic density between crystallites and amorphous regions in iPP and the other associated with the presence of $\mathrm{TiO}_{2}$ in the resulting materials.

To analyse only the characteristics of polymeric crystallites, the second contribution mentioned above has been subtracted, as depicted in the patterns shown in Fig. 9. Additional information can then be obtained from these profiles by analysing the relative SAXS invariant ${ }^{44-46}$ for films processed under the two thermal treatments (upper plots in Fig. 10). These results are evidence for the existence of different regions in both types of specimens ( $S$ and Q): an initial region, up to $c a 55^{\circ} \mathrm{C}$, where a very small increase of the SAXS invariant is detected; a second zone, between 55 and ca $130^{\circ} \mathrm{C}$, where a more important increase of the invariant is seen; and a third zone above $130^{\circ} \mathrm{C}$ that is well characterized by a primary and sharp decrease related to the main melting process (as will be discussed later on).

These regions can be also observed in the lower plots of Fig. 10, where the values of the most probable long spacing $(L)$ deduced from the Lorentz-corrected SAXS profiles are plotted as a function of temperature: the first region, up to $c a 55^{\circ} \mathrm{C}$, where $L$ is almost constant; a second region, between 55 and $c a 130^{\circ} \mathrm{C}$, with a moderate increase of $L$; and a final one, with a very important thickening, attributed to a considerable melting-recrystallization phenomenon.

It is also noticeable that iPPOTi2 under the $\mathrm{S}$ treatment shows a more pronounced increase of its invariant during the second stage (upper left plot in Fig. 10), probably because of poor interfacial adhesion between iPP polymer and $\mathrm{TiO}_{2}$ nanoparticles. This effect is not observed for the $Q$ sample due to the fact that crystallite formation occurs under conditions far away from equilibrium and differences between the non-compatibilized iPPOTi2 sample and those that incorporate the interfacial agent are minimized. A comparison between $\mathrm{S}$ and $\mathrm{Q}$ samples (left and right lower plots in Fig. 10) indicates that values of most probable long spacing for the whole temperature interval obtained for the $\mathrm{S}$ specimens are higher than those found for the $\mathrm{Q}$ specimens. This is attributable to the more favourable crystallization conditions prevailing in the case of the S specimens, which allow a major development of crystallites and, consequently, their perfection. It is also important to note that for a given thermal history, thicker crystallites are formed in the nanocomposites than in the neat iPP matrix, probably due to the nucleant effect of the $\mathrm{TiO}_{2}$ nanoparticles. 

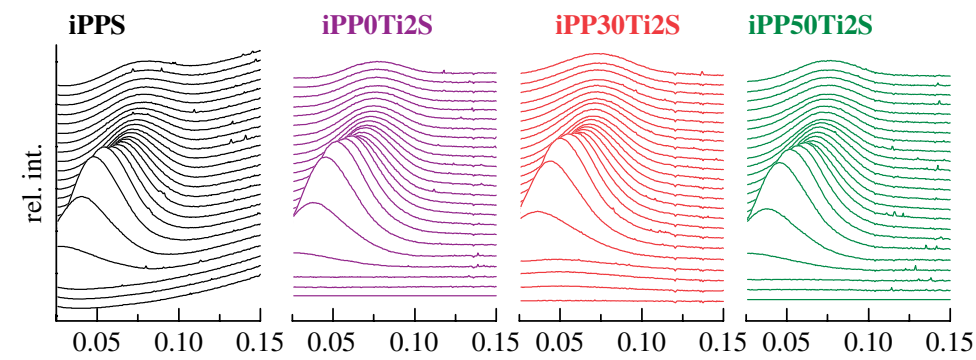

iPP80Ti2S
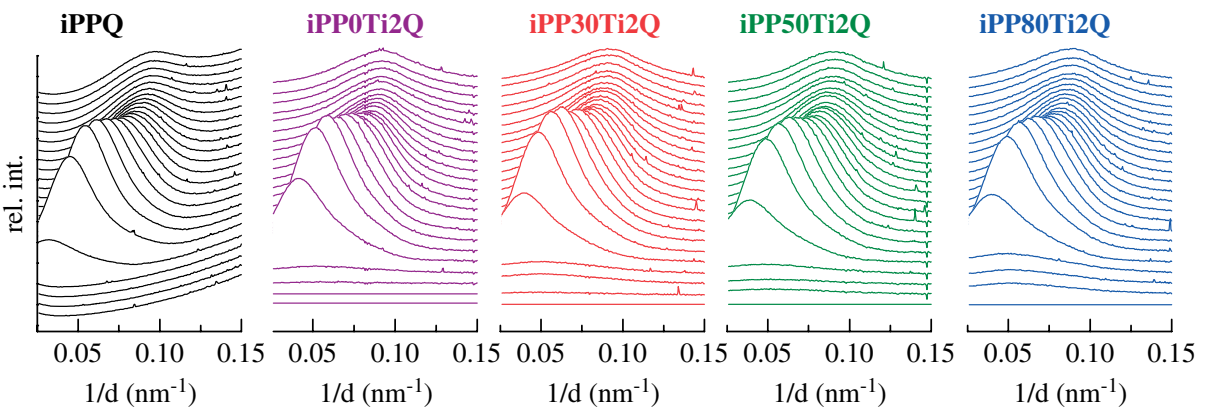

Figure 9. Real-time SAXS profiles related to the iPP behaviour by subtraction of last frame, obtained with synchrotron radiation for all samples under the two thermal treatments in a melting experiment at $8^{\circ} \mathrm{C} \mathrm{min}^{-1}$. Only one in every three frames is plotted for clarity.
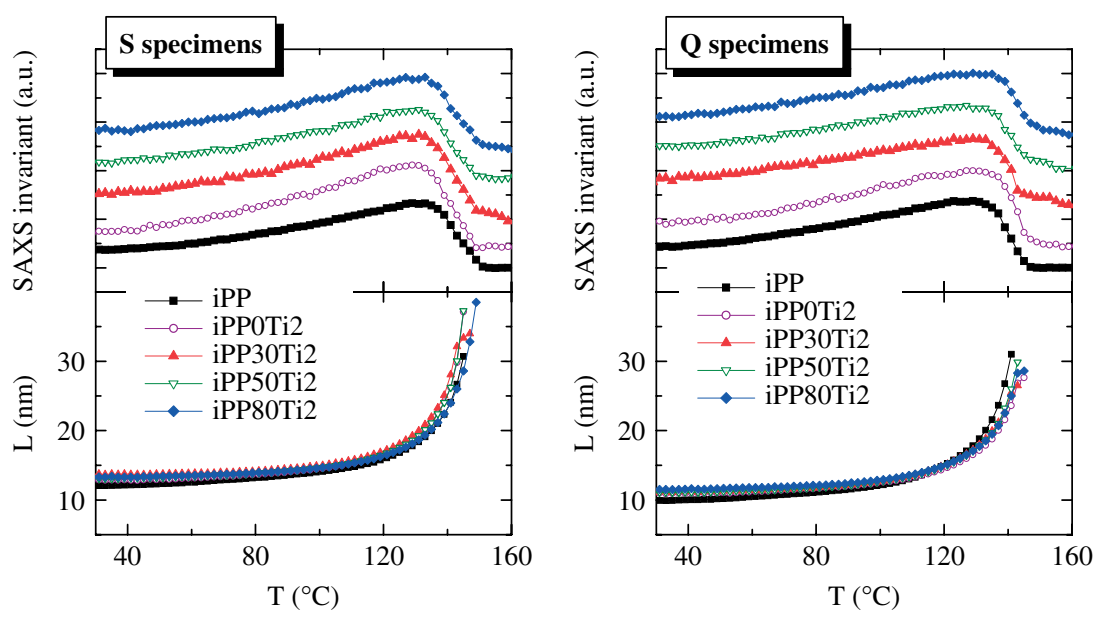

Figure 10. Effect of temperature on the relative SAXS invariant (upper plots) and Lorentz-corrected long spacing (lower plots) obtained during the first heating process for iPP homopolymer and various nanocomposites processed under $\mathrm{S}$ and $\mathrm{Q}$ thermal treatments.

This will be further commented on when the DSC experiments are discussed.

More information is obtained from the corresponding derivatives of the relative invariant shown in Fig. 11 for two of the samples. These derivatives are rather similar to the DSC melting endotherms (also depicted in Fig. 11 for these two specimens as examples), these two types of experiments allowing one to obtain additional information. Again, various zones are distinguished: a smooth exothermic process related to thickening of the initial thinner crystallites followed by the main endothermic melting.

The DSC results corresponding to the first heating run (Fig. 11) depend strongly on the thermal history imposed on a given sample. Two clear endothermic peaks are observed for the $\mathrm{S}$ samples within the temperature interval $125-150^{\circ} \mathrm{C}$. They are ascribed to the melting of both polymorphs present in iPP and in each hybrid. The peak that occurs at low temperatures is related to the $\gamma$ crystallites whereas the one associated with the $\alpha$ form occurs at a slightly higher temperature. ${ }^{47}$ The two melting temperatures have been estimated and their values are listed in Table 2. These two endothermic processes can be seen because the amount of $\gamma$ crystallites is high enough as revealed from WAXS results. In contrast, the $\mathrm{Q}$ specimens exhibit a single endothermic peak ascribed to the melting process of the $\alpha$ form (right-hand plot in Fig. 6). The content of the $\gamma$ lattice is in these samples much smaller than in the case of the S specimens and, therefore, its melting is completely merged with that related to the thinnest $\alpha$ crystallites and it is not discernible at the heating rate used.

The calorimetric curves prove that melting starts at low temperatures, far from the main melting processes, but they are unable to provide more specific details that can be obtained from real-time SAXS experiments. From these tests it is possible to observe that the enhancement of the crystallites starts at ca $60{ }^{\circ} \mathrm{C}$ through the small exothermic process mentioned above. The presence and, consequently, the melting of the $\gamma$ and $\alpha$ polymorphs cannot be specifically deduced from the SAXS invariant derivatives because of the small difference 

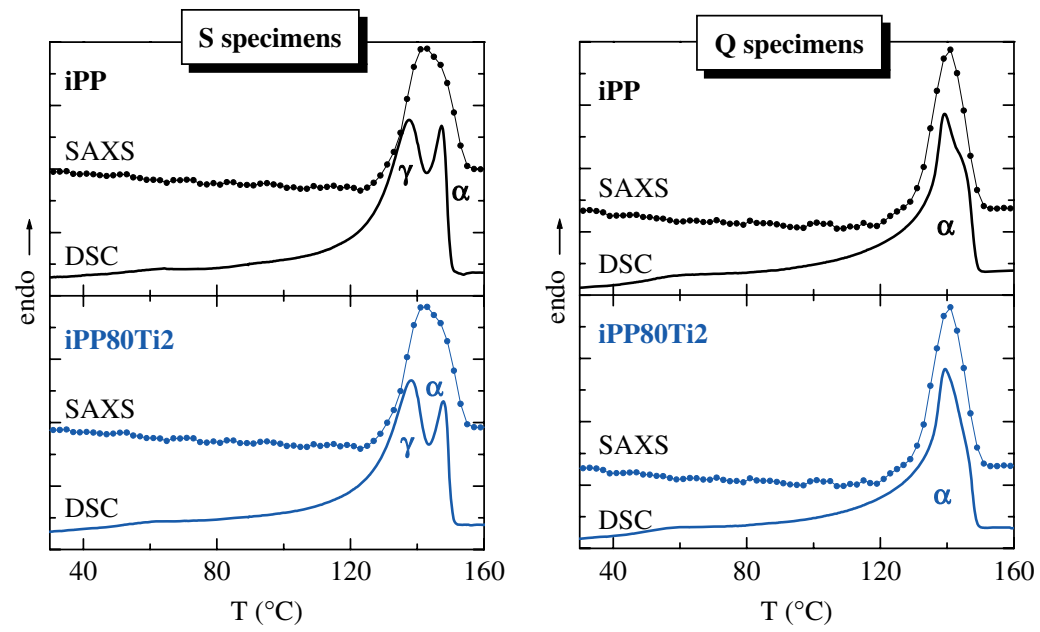

Figure 11. Temperature dependence of SAXS invariant derivatives and calorimetric traces (DSC) for iPP homopolymer and iPP80Ti2 nanocomposite processed under $S$ and $Q$ thermal treatments.

\begin{tabular}{|c|c|c|c|c|c|c|c|c|c|c|c|c|}
\hline \multirow[b]{2}{*}{ Sample } & \multicolumn{6}{|c|}{$\mathrm{S}$ thermal treatment } & \multicolumn{6}{|c|}{ Q thermal treatment } \\
\hline & $f_{c}^{\text {WAXS }}$ & $L^{\text {SAXS }}(n m)$ & $T_{\mathrm{m}}^{\gamma}\left({ }^{\circ} \mathrm{C}\right)$ & $T_{\mathrm{m}}^{\alpha}\left({ }^{\circ} \mathrm{C}\right)$ & $f_{\mathrm{c}}^{\mathrm{DSC}}$ & $T_{\mathrm{c}}\left({ }^{\circ} \mathrm{C}\right)$ & $f_{\mathrm{c}}^{\text {WAXS }}$ & $L(\mathrm{~nm})$ & $T_{\mathrm{m}}^{\gamma}\left({ }^{\circ} \mathrm{C}\right)$ & $T_{\mathrm{m}}^{\alpha}\left({ }^{\circ} \mathrm{C}\right)$ & $f_{\mathrm{c}}^{\mathrm{DSC}}$ & $T_{\mathrm{c}}\left({ }^{\circ} \mathrm{C}\right)$ \\
\hline iPP & 0.61 & 12.1 & 137.5 & 147.5 & 0.51 & 115.5 & 0.54 & 10.2 & - & 139.0 & 0.47 & 115.5 \\
\hline iPP0Ti2 & 0.64 & 12.9 & 137.5 & 147.0 & 0.54 & 116.5 & 0.56 & 11.0 & - & 139.0 & 0.49 & 116.5 \\
\hline iPP30Ti2 & 0.65 & 13.6 & 137.5 & 147.5 & 0.55 & 117.0 & 0.58 & 11.2 & - & 139.0 & 0.48 & 117.0 \\
\hline iPP50Ti2 & 0.64 & 13.1 & 138.0 & 147.5 & 0.55 & 117.0 & 0.56 & 11.1 & - & 139.0 & 0.49 & 117.0 \\
\hline iPP80Ti2 & 0.63 & 13.4 & 138.0 & 148.0 & 0.54 & 117.5 & 0.56 & 11.2 & - & 139.5 & 0.50 & 117.5 \\
\hline
\end{tabular}

a Estimated errors: temperatures, $\pm 0.5^{\circ} \mathrm{C}$; enthalpies, $\pm 4 \mathrm{~J} \mathrm{~g}^{-1}$.

existing between the sizes of both types of crystallites. However, the melting temperature range is obviously broader for the $\mathrm{S}$ specimens than for the $\mathrm{Q}$ ones. The existence of a major content of monoclinic $\alpha$ crystallites in the $\mathrm{Q}$ samples makes dominant the melting-recrystallization phenomenon during their primary melting process.

The degree of crystallinity of the various samples is calculated from the DSC thermograms based on the enthalpy of a perfect polypropylene crystal. For this purpose, an enthalpy of fusion of $209 \mathrm{~J} \mathrm{~g}^{-1}$ was taken for the $100 \%$ crystalline material. The results are reported in Table 2 . The values obtained for the degree of crystallinity for the $\mathrm{Q}$ samples are significantly smaller than those for the S specimens. The total DSC crystallinity is slightly affected by the incorporation of the $\mathrm{TiO}_{2}$ nanoparticles and remains almost unchanged for the various contents of compatibilizer. It is noticeable, however, that the DSC values, for both thermal treatments, are considerably smaller than those deduced from WAXS. This difference can be ascribed to the fact that the enthalpy of fusion exclusively measures the core crystallinity while the crystallinity determined by WAXS takes into account both the core crystallinity and the contribution coming from the ordering within the interfacial regions. Consequently, the values obtained using WAXS are usually higher than those obtained using DSC. ${ }^{48}$

Figure 12 shows the crystallization process for the various samples obtained from the cooling DSC thermograms. Incorporation of
$\mathrm{TiO}_{2}$ clearly has a nucleant effect on the iPP matrix. Consequently, crystallization temperature, $T_{\mathrm{c}}$, is moved to higher temperature (values given in Table 2). Moreover, an increase of crystallization enthalpy is observed. The values obtained are the following: 86,88 , 93, 94 and $95 \mathrm{~J} \mathrm{~g}^{-1}$ for IPP, iPP0Ti2, iPP30Ti2, iPP50Ti2 and iPP80Ti2, respectively. In addition to this nucleant effect, when the compatibilizer is added the crystallization process takes place in a narrow temperature interval. This suggests that there is an improvement in interfacial adhesion between the major iPP component and the $\mathrm{TiO}_{2}$ nanoparticles when the PP-g-MAH compatibilizer is added to the formulation of the nanocomposites. This more intimate contact has been reported previously ${ }^{29}$ and it is also deduced from TEM images (Fig. 1), which prove the better dispersion of $\mathrm{TiO}_{2}$ nanoparticles within the iPP matrix and the smaller size of $\mathrm{TiO}_{2}$ aggregates.

An analysis of the thermal stability under oxidant conditions is mandatory for these nanocomposites because the great interest from a commercial standpoint that they might have. Figure 13 shows the effect that incorporation of $\mathrm{TiO}_{2}$ nanoparticles and interfacial agent has on their degradability. The onset of the degradation in IPPOTi2 is shifted to slightly lower temperatures compared to iPP because of the catalytic effect of $\mathrm{TiO}_{2}$ nanoparticles. The addition of increasing amounts PP-g-MAH increases the stability of the nanocomposites and the temperature of maximum degradation is moved to higher values. Nevertheless, the observed changes in the degradation temperatures of the 


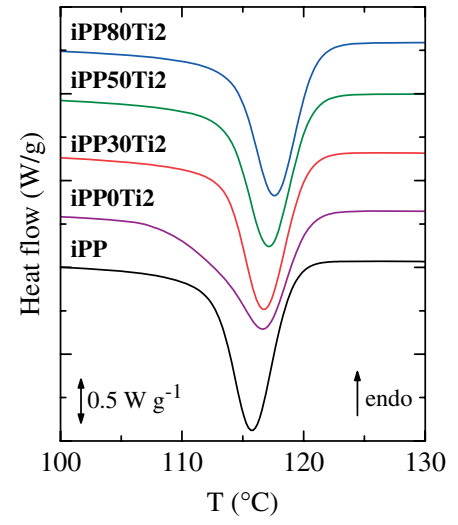

Figure 12. DSC curves corresponding to the cooling process for iPP homopolymer and iPPxTi2 nanocomposites.

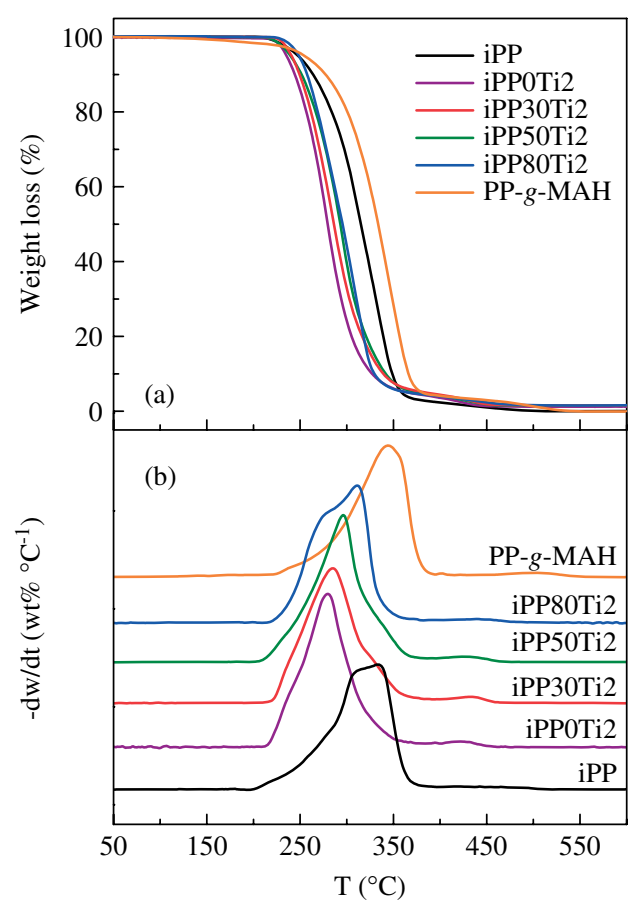

Figure 13. (a) TGA and (b) differential TGA curves of various nanocomposites. Differential TGA curves have been vertically shifted for clarity.

nanocomposites are well within the acceptable levels for their usual end-use requirements.

\section{CONCLUSIONS}

Various $\mathrm{iPP} / \mathrm{TiO}_{2}$ nanocomposites, prepared via a straightforward and cost-effective approach, exhibit a marked ability for destruction of regular microorganisms. Their rheological parameters show small differences, a fact that seems to indicate that $\mathrm{TiO}_{2}$ nanoparticles are accommodated within the polymeric component without a substantial entropic penalty in these iPPxTi2 nanocomposites.

Incorporation of nanoparticles does not interfere with the development of the $\alpha$ and $\gamma$ polymorphs in all the specimens. A majority of $\alpha$ crystals is attained in the $\mathrm{Q}$ samples while a higher proportion of $\gamma$ polymorph is found in the $S$ samples.
An important shift to lower $1 / d$ values of the peak related to the long spacing takes place with temperature. This displacement deduced from SAXS results is ascribed to the improvement in perfection of crystallites and their thickening. Moreover, a periodicity peak, attributed to a characteristic spacing of the $\mathrm{TiO}_{2}$ particles, is observed for all the nanocomposites after melting of the polymeric matrix.

The presence of $\mathrm{TiO}_{2}$ nanoparticles induces a nucleant effect during polymer crystallization, which occurs in a narrow temperature interval when compatibilizer is added, suggesting that there is an enhancement in interfacial adhesion between the major iPP component and the $\mathrm{TiO}_{2}$ nanoparticles when the PP-g-MAH agent is incorporated into the formulation of the nanocomposites.

The onset of the degradation in the nanocomposite without compatibilizer, specimen iPP0Ti2, is shifted to slightly lower temperatures compared with iPP because of the catalytic effect of $\mathrm{TiO}_{2}$ nanoparticles. However, the addition of increasing amounts of PP-g-MAH increases the stability of the nanocomposites and the temperature of maximum degradation is moved to slightly higher values.

Summing up, the nanocomposites under investigation present crystalline characteristics, thermal stabilities and viscoelastic responses in the melt rather analogous to those seen for pure iPP, features that are quite advantageous since the nanocomposites provide an attractive biocidal specificity with almost no change in the properties that influence their processing conditions and those that affect their macroscopic response during their service life.

\section{ACKNOWLEDGEMENTS}

The authors are grateful for the financial support of MICINN (project MAT2010-19883). JA Ressia and EM Vallés acknowledge the financial support from CONICET, FONCyT and UNS. C Serrano is also grateful to MICINN for an FPU predoctoral grant. The synchrotron work leading to these results received funding from the European Community's Seventh Framework Programme (FP7/2007-2013) under grant agreement no. 312284. We thank the collaboration of the Hasylab personnel of the soft-condensed matter beamline A2, especially Dr SS Funari.

\section{REFERENCES}

1 Boisvert J-P, Persello J, Castaing J-C and Cabane B, Colloids Surf A 178:187-198 (2001).

2 Schaller C, Schauer T, Dirnberger K and Eisenbach CD, Eur Phys J C 6:365-376 (2001).

3 Russel WB, Saville DA and Schowalter WR, Colloidal Dispersions. Cambridge University Press, New York (1999).

4 Du F, Fischer JE and Winey KI, J Polym Sci B: Polym Phys 41:3333-3338 (2003).

5 Chapman R and Mulvaney P, Chem Phys Lett 349:358-362 (2001).

6 Yoon PJ, Fornes TD and Paul DR, Polymer 43:6727-6741 (2002).

7 Sinha Ray S and Okamoto M, Prog Polym Sci 28:1539-1641 (2003).

8 Thostenson ET, Li C and Chou T-W, Compos Sci Technol 65:491-516 (2005).

9 Choi S-M and Awaji H, Sci Technol Adv Mater 6:2-10 (2005).

10 Alexandre M and Dubois P, Mater Sci Eng R 28:1-63 (2000).

11 Jordan J, Jacob KI, Tannenbaum R, Sharaf MA and Jasiuk I, Mater Sci Eng A 393:1 - 11 (2005).

12 Biswas M and Ray SS, Adv Polym Sci 155:167-221 (2001).

13 Giannelis EP, Appl Organomet Chem 12:675-680 (1998).

14 Bharadwaj RK, Macromolecules 34:9189-9192 (2001).

15 Sorrentino A, Gorrasi G and Vittoria V, Trends Food SciTechnol 18:84-95 (2007). 
16 Kim BYS, Jiang W, Oreopoulos J, Yip CM, Rutka JT and Chan WCW, Nano Lett 8:3887-3892 (2008).

17 Sangwan P, Way C and Wu DY, Macromol Biosci 9:677-686 (2009).

18 Cheng Q, Bao J, Park J, Liang Z, Zhang C and Wang B, Adv Funct Mater 19:3219-3225 (2009).

19 Li T-L and Hsu SL-C, J Mater Chem 20:1964-1969 (2010).

20 Veca LM, Meziani MJ, Wang W, Wang X, Lu F and Zhang P, Adv Mater 21:2088-2092 (2009).

21 Kubacka A, Serrano C, Ferrer M, Lunsdorf H, Bielecki P, Cerrada ML, et al, Nano Lett 7:2529-2534 (2007).

22 Cerrada ML, Serrano C, Sánchez-Chaves M, Fernández-García M, Fernández-Martín F, de Andrés $\mathrm{A}$, etal, Adv Funct Mater 18:1949-1960 (2008).

23 Kubacka A, Cerrada ML, Serrano C, Fernandez-Garcia M, Ferrer M and Fernandez-Garcia M, J Nanosci Nanotechnol 8:3241 -3246 (2008).

24 Kubacka A, Cerrada ML, Serrano C, Fernández-García M, Ferrer M and Fernández-Garcia M, J Phys Chem C 113:9182-9190 (2009).

25 Kubacka A, Ferrer M, Cerrada ML, Serrano C, Sánchez-Chaves M, Fernández-García M, et al, Appl Catal B 89:441-447 (2009).

26 Nigmatullin R, Gao F and Konovalova V, Macromol Mater Eng 294:795-805 (2009).

27 Khalil M, Saeed S and Ahmad Z, J Appl Polym Sci 107:1257-1268 (2008).

28 Vladimirov V, Betchev C, Vassiliou A, Papageorgiou G and Bikiaris D, Compos Sci Technol 66:2935-2944 (2006).

29 Cerrada ML, Serrano C, Sánchez-Chaves M, Fernández-García M, de Andrés A, Riobóo RJ, et al, Environ Sci Technol 43:1630-1634 (2009).

30 Carp O, Huisman CL and Reller A, Prog Solid State Chem 32:33-177 (2004).

31 Rincón A-G and Pulgarin C, App/ Catal B 49:99-112 (2004).
32 Bahloul W, Bounor-Legaré V, David L and Cassagnau P, J Polym Sci B: Polym Phys 48:1213-1222 (2010).

33 Dangtungee R and Supaphol P, Polym Test 27:951-956 (2008).

34 Fernández-García M, Wang X, Belver C, Hanson JC and Rodríguez JA, J Phys Chem C 111:674-682 (2007).

35 Fuerte A, Hernández-Alonso MD, Maira AJ, Martínez-Arias A, Fernández-García M, Conesa JC, et al, J Catal 212:1 -9 (2002).

36 Ferry JD, Viscoelastic Properties of Polymers. John Wiley, New York (1980).

37 Mansel S, Pérez E, Benavente R, Pereña JM, Bello A and Röll W, Macromol Chem Phys 200:1292-1297 (1999).

38 Wunderlich B, Macromolecular Physics, vol. 3. Academic Press, New York, p. 42 (1980).

39 Jourdan C, Cavaille JY and Perez J, J Polym Sci B: Polym Phys 27:2361-2384 (1989).

40 Cerrada ML, Pérez E, Benavente R, Ressia J, Sarmoria C and Vallés EM, Polym Degrad Stab 95:462-469 (2010).

41 Natta G and Corradini P, Il Nuovo Cimento 15:40-51 (1960).

42 Krache R, Benavente R, López-Majada JM, Pereña JM, Cerrada ML and Pérez E, Macromolecules 40:6871-6878 (2007).

43 Turner-Jones A, Polymer 12:487-508 (1971).

44 Baltá-Calleja FJ and Vonk CG, X-Ray Scattering of Synthetic Polymers. Elsevier, Amsterdam (1989).

45 Ryan AJ, Stanford JL, Bras W and Nye TMW, Polymer 38:759-768 (1997).

46 Crist B, J Polym Sci B: Polym Phys 39:2454-2460 (2001).

47 Hosier IL, Alamo RG, Esteso P, Isasi JR and Mandelkern L, Macromolecules 36:5623-5636 (2003).

48 Isasi JR, Mandelkern L, Galante MJ and Alamo RG, J Polym Sci B: Polym Phys 37:323-334 (1999). 